\title{
La más sensorial de las profesiones. El papel de los sentidos en la comunicación médica
}

\author{
María GONZÁleZ GARCíA, Begoña CANTABRANA, Agustín HIDALgo
}

Área de Farmacología (Departamento de Medicina). Facultad de Medicina y Ciencias de la Salud. Universidad de Oviedo (España). Instituto Universitario de Oncología del Principado de Asturias. Fundación Bancaria Caja de Ahorros de Asturias. Instituto de Investigación Sanitaria (ISPA) (España).

Autor para correspondencia: Agustín Hidalgo. Correo electrónico: hidalgo@uniovi.es

Recibido el 18 de abril de 2019; aceptado el 2 de mayo de 2019.

Como citar este artículo: González García M, Cantabrana B, Hidalgo A. La más sensorial de las profesiones. El papel de los sentidos en la comunicación médica. Rev Med Cine [Internet] 2019;15(2): 107-19.

DOI: http://dx.doi.org/10.14201/rmc2019152107119

\section{Resumen}

La observación del enfermo es un elemento crítico de la anamnesis y el diagnóstico médico. Si bien el desarrollo científico y técnico puede aportar información de gran valor, el uso de los sentidos, fundamentalmente de la vista, el oído y el tacto, es importante en el acto médico tanto por la información que aportan como por la interacción humana con el enfermo. El sentido de la vista informa de alteraciones morfológicas y funcionales; el del oído permite discernir entre normalidad y patología en el funcionamiento visceral; el del tacto informa sobre cualidades de determinadas afecciones, además de aportar el componente mitológico/religioso de la sanación por imposición de manos. Pero, por otra parte, el enfermo puede utilizar los sentidos para obtener información y extraer conclusiones sobre el comportamiento del médico a través de los gestos, la expresión verbal, la presencia y actitud, e incluso el olor percibido en la interacción entre médico y el enfermo.

Palabras clave: sentidos, exploración médica, diagnóstico, relación médico-paciente, percepción del médico por el paciente.

\section{The most sensory of the professions. The role of the senses in medical communication}

\begin{abstract}
Summary
The observation of the patient is a critical element of the anamnesis and medical diagnosis. Although the scientific and technical development can provide information of great value, the use of the senses, fundamentally sight, hearing and touch, is important in the medical act both for the information they provide and for the human interaction with the sick. The sense of sight informs of morphological and functional alterations; that of the ear allows to discern between normality and pathology in visceral functioning; the one of the touch contributes information on qualities of certain affections, besides contributing the mythological / religious component of the healing by imposition of hands. But, on the other hand, the patient can use the senses to obtain information and draw conclusions about the behavior of the doctor through gestures, verbal expression, presence and attitude, and even the smell perceived in the interaction between doctor and sick.
\end{abstract}

Keywords: Senses, Medical Exploration, Diagnosis, Doctor-patient relationship, Perception of the doctor by the patient.

Los autores declaran que el artículo es original y que no ha sido publicado previamente. 


\begin{abstract}
"La labor del médico es saber en primera instancia las cosas más importantes, más conocidas, que deben percibirse mediante la vista, el contacto, el oído, el olfato y el sabor" (Hipócrates ${ }^{1}$ )
\end{abstract}

\section{Introducción}

Los humanos necesitamos los cinco sentidos para percibir y sentir el mundo, para sentirnos inmersos en él y partícipes de esa empresa a la que llamamos vivir en relación con el entorno. En este sentido se manifiesta Miguel Ángel Criado ${ }^{2}$ en su artículo titulado La jerarquía casi universal de los cinco sentidos en el que se hace eco de un estudio de la Fundación Max Planck que ha evaluado la prevalencia de los sentidos en el lenguaje mediante la frecuencia de uso de palabras que se refieren a ver, oír, tocar, etc. El análisis de los registros de conversaciones cotidianas de personas de diferentes culturas, que hablan en 13 idiomas, revela que la vista es el sentido al que damos más importancia ya que el $60 \%$ de los vocablos referidos a sentidos están relacionados con ver, posiblemente porque es el sentido más usado. Le siguen el oído, el tacto, el sabor y el olor, aunque puede haber diferencias culturales. De forma análoga, en la encuesta sobre los Sentidos'09, el 92\% de los encuestados considera que el sentido más importante es el de la vista, y el $71 \%$ el del oído, siendo los menos valorados el sentido del olfato y el gusto ${ }^{3}$.

El uso y la contribución de los cinco sentidos está fuera de toda duda por lo que podemos considerar a la medicina una profesión muy sensorial, de forma análoga a como lo estima Lisa Sanders": "La medicina -en la medida en que puede ser considerada una ciencia- es una ciencia sensorial, una ciencia en la que se recopilan datos sobre el paciente a través del taco y de otros sentidos siguiendo un método sistemático a fin de elaborar un diagnóstico. La mayoría de los pacientes están dispuestos a que los toquen sus médicos. Lo esperan". De forma similar, el profesor Miquel Vilardell 5 indica que "debes utilizar todos los sentidos para efectuar esta observación: mirar, escuchar y oler son operaciones esenciales mucho antes de llegar a tocar al paciente, y en ciertas circunstancias, incluso pueden ser suficientes para llegar a establecer un diagnóstico".

Por tanto, la medicina obtiene información a través de todos los sentidos y explora la integridad y/o afectación de todos ellos con fines diagnósticos o terapéuticos, hasta el punto de que las deprivaciones sensoriales de los médicos pueden limitar su ejercicio profesional. Por eso es tan importante la educación de los sentidos durante la formación de los estudiantes de Medicina. Oliver Sacks lo recuerda así durante sus años de formación: "Ia enseñanza esencial se llevaba a cabo junto a la cama del paciente, y la lección esencial consistía en escuchar, en comprender el "historial de la dolencia actual" de labios del paciente y hacer las preguntas adecuadas para conocer los detalles. Se nos enseñaba a utilizar los ojos y los oídos, a tocar, a palpar, e incluso a oler. Escuchar el latido de un corazón, percutir el pecho, palpar el abdomen y otras formas de contacto físico eran no menos importantes que escuchar y hablar. Podrían establecer un vínculo físico y profundo; las propias manos se podían convertir en herramientas terapéuticas"6.

De forma equivalente, la SEMFYCEX7 nos recuerda que "los principales recursos del médico de Atención Primaria serán su buena relación con el paciente y la familia, su capacidad intelectual, el uso apropiado de sus manos, ojos y oídos, así como una gran sensibilidad humana". Y es que los sentidos aportan buena parte de los componentes de arte que caracterizan la actividad profesional de la medicina aunque, desde hace tiempo, el diagnóstico ya no es "un pronóstico del médico a partir del pulso y el bolsillo del paciente"4 sino un complejo discurso científico con el concurso de tecnologías avanzadas aunque no exento de incertidumbres. Por eso es tan importante educar los sentidos de los futuros médicos empezando durante los estudios de Grado ${ }^{8-10}$ porque "la formación en una sistemática exploratoria con la correcta interpretación de los signos, ha de seguir siendo una piedra angular en la formación del futuro médico"11,12.

En tiempos no tan lejanos, los médicos, raras veces realizaban un examen del cuerpo del paciente y se contentaban con la utilización de los "cinco sentidos" para emitir un diagnóstico: observar de lejos el color de la piel, oír las irregularidades de su respiración, olerlo, probar el sabor de su orina y tomar el pulso"13. Sin embargo, la tecnología ha transformado el espacio corporal en casi transparente. Si bien los sentidos continúan teniendo un valor innegable en el acto médico, y proporcionan "una importante contribución a nuestra capacidad para entender al paciente y su enfermedad" no faltan opiniones que sugieren que tanto los médicos como los pacientes "parecen estar dispuestos a abandonar la exploración física tan concienzudamente desarrollada durante los dos últimos siglos; su desgaste avanza sin ningún tipo de restricción"4.

A continuación comentamos brevemente algunos aspectos de la contribución de los sentidos al acto médico. 


\section{Sentido de la vista}

La vista se ha considerado durante mucho tiempo el más importante de los cinco sentidos. De hecho, más del $50 \%$ del cerebro humano está dedicado a ella. En la relación entre el médico y el enfermo, el primer contacto se produce a través de la vista. El médico se hace una primera composición de lugar a través de la vista, a través de la cual percibe características somáticas (edad, tamaño, constitución, aspecto, etc...), funcionales (estado nutricional, movilidad, carencias potenciales, etc.), emocionales (enfermo vital, huidizo, desconfiado, reticente, etc.) e incluso afectivos si conoce o no al enfermo.

Un médico bueno y un buen médico debe tener capacidad de observación. Indica Vilardell5 que "Cuando alguien entre en la consulta, la primera impresión, si eres observador, te da las primeras pistas que te conducirán después al lugar al que quieres llegar". Y continúa diciendo que a esta capacidad de observación es a lo que llamamos "ojo clínico" e invoca la conocida expresión: "este tiene ojo clínico, con sólo verme, ya me ha dicho lo que me pasaba".

De esta visualización inicial del enfermo, el médico extrae los elementos más aparentes de las afecciones y formulará las primeras conjeturas sobre los motivos de la visita que luego completará con una cuidadosa anamnesis y el concurso de los otros sentidos: ¿Es joven o viejo? ¿Tiene aspecto enfermizo o saludable? ¿Cómo anda? ¿Manifiesta dolor? El primer encuentro puede transcurrir más o menos como en la visita que realiza el enfermo Elmo Turner a su médico, el internista Dr. Richard L. Wooten que podemos leer en la historia de EI hombre naranja14 en los siguientes términos: "Se abrió la puerta y entró Turner, un hombre bajo, recio y musculoso. El doctor se había levantado para saludarlo, pero por unos instantes lo contempló asombrado: Turner tenía la cara de color naranja, de un tono dorado, como de calabaza, y las manos del mismo color. (...) El doctor Wooten lo escuchaba a medias, ya que estaba pensando en todas las posibles enfermedades capaces de producir decoloraciones patológicas de la piel. Había muchas patologías con manifestaciones pigmentarias: la palidez extrema de las enfermedades de la pituitaria, el azul cianótico de las enfermedades congénitas del corazón, el profundo bronceado de la disfunción del tiroides, el amarillo derivado de un mal funcionamiento del hígado, el tono bronceado de la hemocromatosis. Sin embargo, por lo que él sabía, ninguna enfermedad daba a sus víctimas ese color naranja"14.

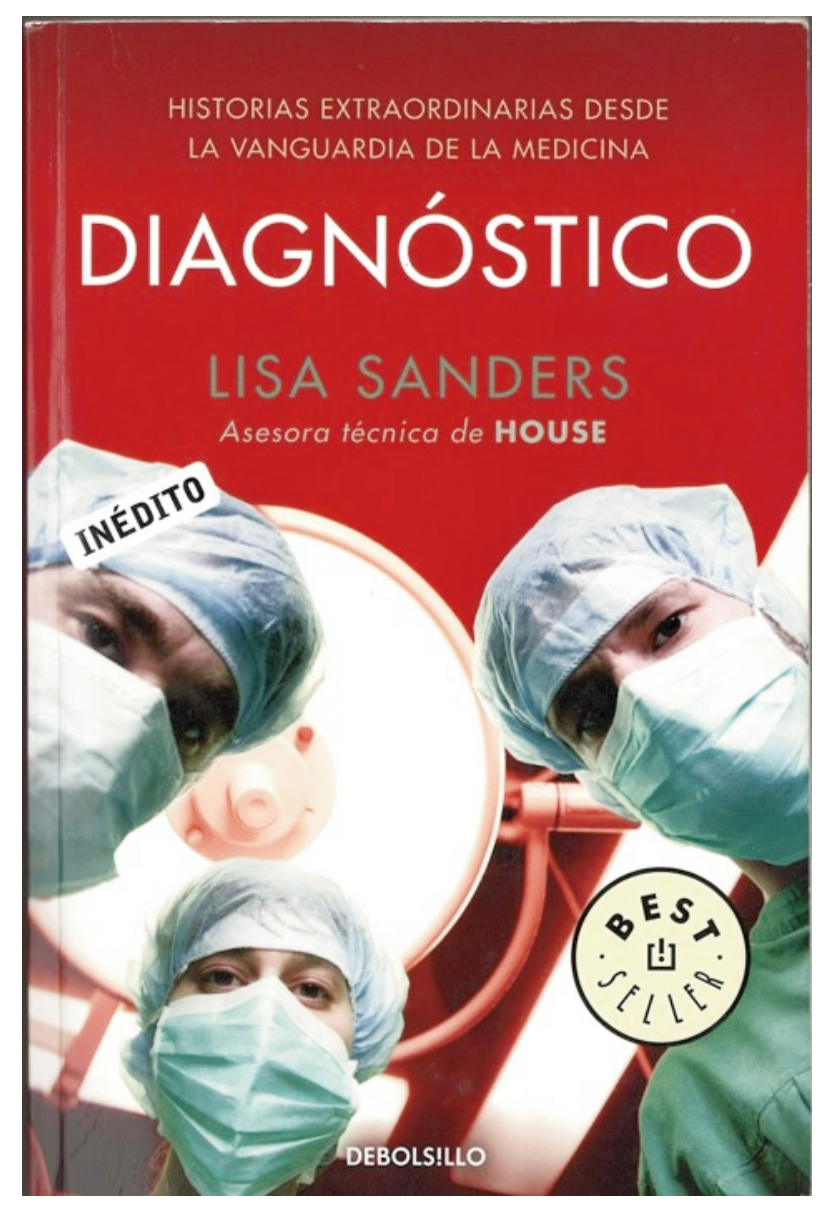

Sin embargo, los cambios operados en la asistencia sanitaria por la evolución científico-técnica y por las modificaciones estructurales de los centros asistenciales y por la propia culturización de la sociedad poco tienen que ver con aquellas visitas a la consulta de un médico que se levantaba de la silla, acudía a estrechar su mano, le invitaba a sentarse, charlaba con él de toda la historia clínica familiar y le acompañaba a la salida. Hoy, la imagen del médico que, mayoritariamente, obtiene el enfermo en la visita a la consulta es la de un profesional distante, poco empático, que le recibe sentado, generalmente mirando una pantalla de ordenador, a la que presta más atención que a ti mientras le cuentas los motivos de la visita, que no te toca si puede evitarlo y que no te acompaña a la salida. Esta situación también es percibida como poco adecuada al acto médico por algunos profesionales, sobre todo los más veteranos que han podido ejercer una relación médico-paciente más próxima y humana: "Desde que tienen ordenador, los médicos no miran a los pacientes a la cara", sostiene, entre otros, el doctor Carlos Jiménez Escolano ${ }^{15}$, ahora jubilado. Y tiene razón. 
Otro ejemplo de la descripción minuciosa de lo observado, la tomamos del libro Diagnóstico, de Lisa Sanders": "tenía la piel blanca, salpicada de manchas rojas y escamosas, un indicativo de que había pasado demasiadas horas al sol. La oreja que le había llevado inicialmente al hospital estaba inflamada y deformada por una lesión roja y prominente que tenía en la punta. Sus mejillas sin afeitar, estaban descarnadas y se le marcaban mucho los pómulos; sus ojos parecían enfocar algo de la habitación que nadie más podía ver. Llevaba flequiIlo, de pelo cano, bien cortado aunque despeinado...".

Por tanto, parece claro que en la exploración todo es mirar y ver. El médico "observa la piel y los ojos, mira dentro de las orejas y de la boca; comprueba el color de la lengua, las uñas, las heces. Muchos de los utensilios utilizados para realizar la exploración permiten ver mejor las orejas, la nariz, la boca; el equipo utilizado para medir la tensión arterial, la temperatura, la saturación de oxígeno o la concentración de glucosa en sangre facilita los datos por medios visuales. Las pruebas solicitadas para obtener información adicional sobre el paciente a menudo transforman los datos en representaciones visuales: las técnicas de diagnóstico por imagen son el ejemplo más claro, pero un electrocardiograma es una representación visual de la actividad eléctrica del corazón, y un electroencefalograma lo es del circuito de trabajo" 4 . En consecuencia, parece necesario que abordemos de forma precoz el adiestramiento de los estudiantes en el arte de mirar, una iniciativa que ya han iniciado algunas españolas y otras de fuera de nuestras fronteras ${ }^{9,10}$.

Laín Entralgo16, en El médico y el enfermo, indica que la mirada del enfermo es petitiva porque ve en el médico "una realidad capaz de ayuda". Dice también que la mirada del médico expresa tres intenciones principales: a) una intención envolvente (de refugio a la existencia menesterosa del paciente), b) una intención inquisitiva (dirigida tanto al conjunto como a los detalles del cuerpo como al interior de su alma, y c) una intención objetivante (cuando el médico encuentra lo que busca o halla algo que no buscaba lo objetiva y contextualiza en el marco de la historia clínica). Más recientemente, Cristobal Pera ${ }^{13}$ sugiere que actualmente se han consolidado distintas miradas médicas más allá de la mirada personal del médico al paciente, como son la "mirada médica corporativa (corporaciones médicas, sociedades de asistencia sanitaria), la nacionalizada (servicios nacionales de salud) y la globalizada (Organización Mundial de la Salud)" que han desplazado hacia la salud los esfuerzos de la lucha contra la enfermedad, incluyendo en la mirada médica el componente preventivo y social más allá del curativo. Pero, por encima de todo, "la mirada médica debe ser una mirada justa y compasiva, cuyas múltiples acciones se fundamenten en una primordial relación narrativa entre el paciente, con su historia personal, y el médico, con su lectura de dicha historia"17.

Pero en ese primer intercambio visual, también el paciente y sus acompañantes tendrán la primera impresión del médico que irán aquilatando a lo largo de la visita y, cuando sea el caso, del trato frecuentes en visitas ulteriores. De ahí la importancia que al aspecto y a la conducta del médico en la consulta se le ha dado tradicionalmente como elementos indispensables de una buena relación médico-paciente y de la necesaria confianza del enfermo en el médico. Los cinco sentidos de los enfermos y de sus familiares también pueden describirle a Vd., como hace Sergio del Molino de algunos de los médicos que atendieron a un hijo suyo: "Si Carlota es una sacerdotisa entregada, Ana, sin ser menos firme en

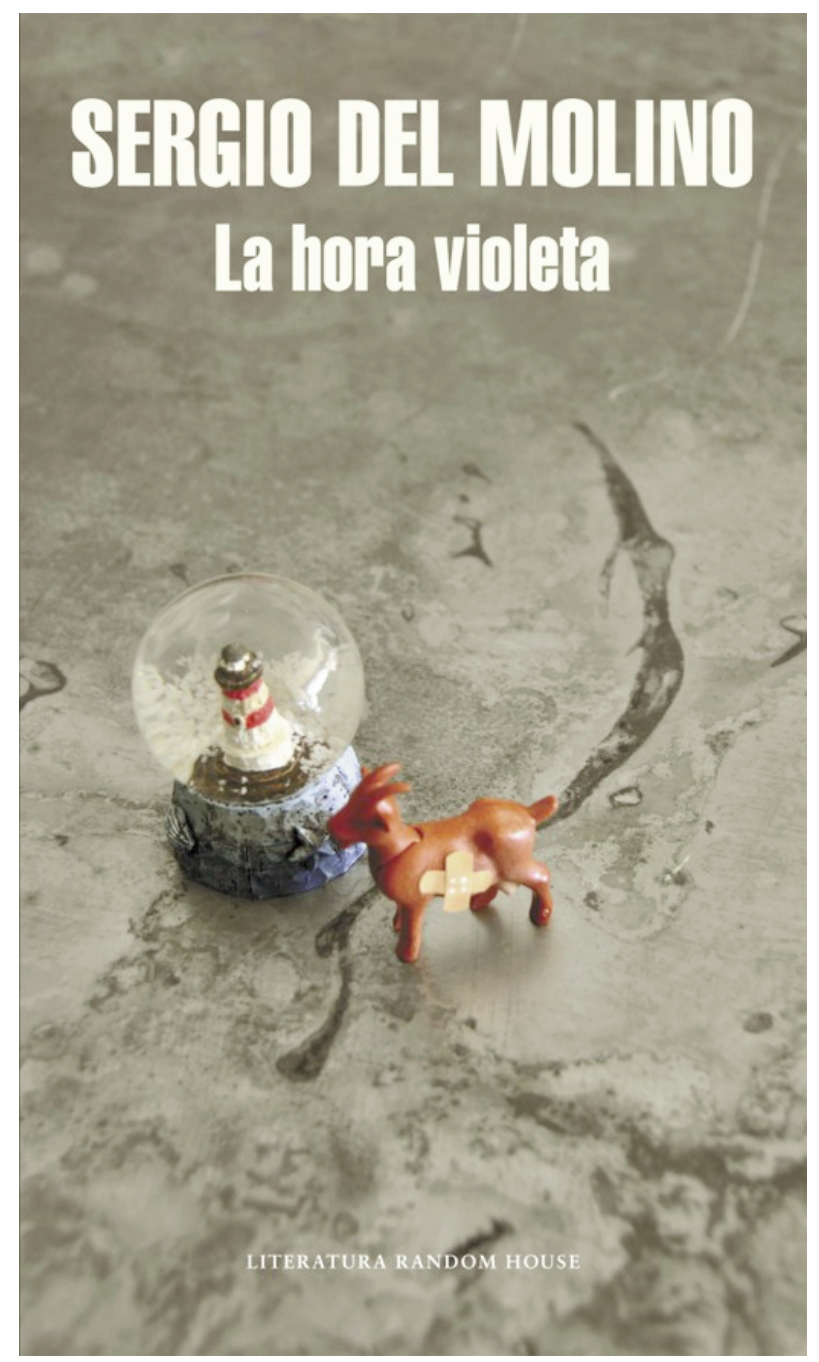


Tabla 1. Lo que los médicos deben cuidar en su comunicación con el paciente porque los enfermos lo verán 39 .

No debe gesticular demasiado ni estar rígido y envarado.

Los movimientos de las manos deben ser correctos. Gesticular demasiado genera nerviosismo e inquietud.

Las manos deben estar visibles, preferentemente cruzadas encima de la mesa. También al estar de pie, las manos deber estar visibles.

El cuerpo debe estar relajado, pero erguido, sin tensión, en una postura abierta, sin cruzar las piernas ni posturas retorcidas.

El médico siempre debe estar a la misma altura que el paciente; los dos de pie o ambos sentados. Cuando exploremos al paciente, el médico debe estar sentado, para aproximarse a la postura en decúbito del enfermo.

El rostro del profesional debe ser humano, no una facies inexpresiva, seca y una máscara sin sentimiento, ni abusar de expresiones exageradas y locuaces.

La mirada del profesional debe ser franca, abierta y denotar atención, propio de la escucha activa. El paciente debe ser consciente de que estamos prestándole atención, que en ese momento ellos son los más importantes.

El médico debe mirar al enfermo en toda su profundidad, sin agresividad, no de manera inquisitorial sino de un modo relajado y dulce, apoyada con una leve sonrisa. Esta mirada debe ser capaz de transmitir confianza y seguridad, interés, capacidad de resolver problemas, dulzura y, por qué no decirlo, cariño.

su compromiso, no ha descuidado lo mundano. Impecablemente vestida, muy elegante, una melena perfecta y unos modales suaves y un punto señoriales"18.

Pero también, los pacientes intentarán leer en su expresión facial, el pronóstico de su enfermedad: "Me miró y supe que algo iba mal"4 es la lectura que hace una enferma de la expresión de su radiológico al finalizar la mamografía que le había practicado. Por ello, es importante que los médicos sean conscientes de que sus palabras y sus gestos serán interpretados por los enfermos y su entorno. De hecho, la SEMFYCEX propone a sus médicos, en el "Decálogo del buen médico", "recordar el lenguaje extraverbal, que muchas veces es más importante que el verbal", sobre todo ante situaciones delicadas y/o graves porque "Algunos pocos pacientes verán el fracaso en el rostro del profesional"19.

Abunda Juan Gracia Armendáriz, periodista con muchas horas de hospital por su enfermedad renal, en su Diario del hombre pálido, sobre algunas características del personal sanitario. Escribe de la médica que le atiende: "la sonrisa no es un hábito que cultive". Y de las enfermeras: "Todas están malhumoradas, son vulgares, malencaradas. Me pregunto si han recibido su formación sanitaria en un hospital estalinista"20. En otra de sus obras, Piel roja, continúa con las alusiones: "Por la tarde me visita el nefrólogo triste. Lleva sobre su espalda todo el peso del mundo. (...) Con idéntica tristeza me da el alta médica"21; "No tardó en aparecer una enfermera de rostro sanguíneo, fuerte como un hombre. Debía de practicar musculación. Era la veterana de la planta, su rostro era adusto y su voz tabacosa. Por su cutis y sus ojos abultados, le diagnostiqué un problema en la hipófisis"21; "El lenguaje corporal del nefrólogo indica que trae buenas noticias"21. Por estas y otras cuestiones similares, se han establecido una serie de cuestiones que el médico (y en general el personal sanitario) debe cuidar en la comunicación con el enfermo (Tabla 1).

Si bien "los ojos son testigos más exactos que los oídos"1, o como dice una sentencia popular "los oídos son más dignos de fe que los ojos", no es menos cierto que no sólo se puede observar con los ojos.

\section{Sentido del Oído}

La comunicación entre el médico y el enfermo se basa, además de en la vista, en el oído. El vehículo de expresión, la palabra, necesita del sentido del oído para que la comunicación sea plena, para que lo que el enfermo dice llegue a conocimiento del médico, para que lo que el médico inquiere o sugiere tenga la necesaria respuesta, para que entre ambos se vaya conformando una conexión de confianza mutua, una solicitud de ayuda y un ofrecimiento certero y sincero. 
De forma análoga al sentido de la vista, el oído aporta una cantidad importante de información, no sólo orientada al diagnóstico sino también al seguimiento de la evolución de la enfermedad, a las modificaciones producidas en la misma por la actuación profesional y a los aspectos más humanos involucrados en el ejercicio de la medicina, como la calidad del trato en los servicios sanitarios, sus vivencias sobre las listas de espera, las incertidumbres, etc. lo que requiere adquirir experiencia en el arte de escucha (Tabla 2 ) y ser conscientes de que "la Escucha activa es una buena terapia" 22 .

"El médico, decía Osler, tiene dos oídos y una boca precisamente para escuchar el doble de lo que habla"7. Este aserto, incorporado por la sociedad Extremeña de Medicina Familiar y Comunitaria en su "Decálogo del buen Médico" indica claramente que el médico prudente ha de dedicar el tiempo necesario a escuchar a los enfermos y a sus familiares para recabar la mayor cantidad de información posible para comprender al paciente y a la enfermedad que le aqueja, conscientes de que no saber oír adecuadamente puede conducir a errores. Así mismo, "escuchar con atención las narraciones de los pacientes ha constituido una parte esencial de las actuaciones de las fundadoras del movimiento de cuidados paliativos $y$, sin duda, lo es para los actuales profesionales paliativistas" 23 . Y para todos los médicos, debemos añadir.

El oído del médico debe estar entrenado en la percepción de matices tanto verbales como orgánicos. En el primer caso, el médico debe diferenciar en el tono de voz del enfermo la aprensión, la intensidad, el miedo, la decisión, etc. ante la enfermedad y adecuar su expresión a las dimensiones vivenciales del enfermo. En el segundo caso, el oído del médico diferencia los "ruidos" a través de los que los latidos cardiacos, la trama bronquial, las asas intestinales, ..., informan del estado funcional de las vísceras. No obstante, la adquisición de la destreza es lenta y requiere considerable esfuerzo porque, por ejemplo, "la exploración física del corazón es un ejercicio sutil que requiere habilidades muy bien desarrolladas para detectar las ligeras variaciones de los sonidos cardíacos"4.

Por otra parte, no debemos olvidar, que el sentido del oído fue uno de los primeros en ser instrumentalizado mediante el fonendoscopio24. Corría el año 1816 y se planteó el problema de examinar a una gruesa joven con dolor en el pecho. La práctica habitual de auscultación mediante la colocación de la oreja sobre el pecho del enfermo parecía tan ineficaz, a causa de la gran cantidad de grasa, como impropia. En esta situación Laennec

Tabla 2. Razones por las que los médicos deben aprender a escuchar de formas diferentes a sus enfermos: (Cualidades y ventajas de escuchar con atención) ${ }^{22}$.

Tiene el poder de llevar adelante una conversación o no.

Captaremos su atención mantenida interesándolo en nuestra atención.

Permite conocer en profundidad qué enfermedad padece el paciente, dónde, cuándo y de qué manera se presenta, ya que el paciente se comunica y el médico descifra e interpreta en clave médica técnica y humanamente lo que le puede estar sucediendo.

Descubriremos su forma de ser tirando del hilo y, por tanto, los pacientes serán más previsibles.

Se experimenta alivio. El paciente en ocasiones siente como vergonzante sus motivos de consulta y no los expresa en primer término.

Se llega a sentir cómodo para recibir asesoramiento médico.

La responsabilidad de la curación debe ser compartida y consensuada con el enfermo al que se debe hacer partícipe.

Ejerce la paciencia.

Hace amigos o al menos mantiene unas relaciones armónicas con los demás.

Si durante la entrevista debe interrumpirla es mejor decir: disculpe, estoy con usted en un momento, que no decirle nada y ausentarte durante un tiempo indeterminado.

Sobre todo, es importante que se sientan cómodos, sin prejuzgarles jamás. 
recordó un fenómeno acústico bien conocido: "si se apoya una oreja en el extremo de un palo, la percusión de un alfiler se puede escuchar claramente en el otro extremo. Imaginé que esta propiedad de los materiales podía aplicarse en este caso. Arranqué una hoja de una librea de notas y la enrollé sobre sí misma. Apoyé un extremo sobre el área precordial y coloqué una oreja sobre el otro. Quedé tan sorprendido como satisfecho cuando escuché el latido del corazón, de un modo mucho más nítido y preciso que directamente con la oreja" 25 . El dispositivo ha terminado llamándose estetoscopio (de stethos = pecho). Fue el primer desarrollo tecnológico que permitió una "visualización" del trabajo interno del cuerpo. Este descubrimiento contribuyó, sin lugar a dudas, al comienzo de un avance importante en la medicina: obtener información directa de alteraciones funcionales de órganos internos, diseccionar por la acústica lo normal de lo patológico venciendo los reparos de la aplicación directa del oído al cuerpo del enfermo. De esta forma, "la auscultación mediada por el estetoscopio hacía posible llevar a cabo una autopsia virtual que permitía visibilizar lo invisible"26. Empezó, también, entonces un distanciamiento entre médicos y enfermos que el desarrollo científico-técnico no ha hecho más que aumentar.

Sin embargo, el desarrollo tecnológico ha reducido el valor del sentido del oído, aunque nos ha aportado más desasosiego. Susan Sontag27 lo describe así: "En los viejos tiempos de los diagnósticos artesanales, la auscultación daba un veredicto inmediato, tan inmediato como fuera la voluntad de hablar del médico. Ahora una auscultación implica un análisis. Y los análisis introducen un lapso que, dado el carácter inevitablemente industrial del test médico competente, puede durar semanas: una demora angustiosa para quienes piensan que están esperando una sentencia de muerte o una absolución. Muchos se resisten al análisis por el temor al veredicto, por el mero miedo a que se les ponga en una lista que podría acarrearles discriminaciones futuras o cosas peores, y por fatalismo (¿de qué puede servir?)".

Por último, y como decíamos anteriormente, el enfermo y sus familiares escucharán con atención, explorarán e interpretarán las palabras del médico tanto en un sentido denotativo como connotativo: "Cualquiera palabra, cualquier inflexión en la voz, cualquier gesto, nos sirve para aguantar un día más. Pueden darnos la alegría o quitárnosla con una simple mueca"18. Esto justifica las recomendaciones recogidas en la Tabla 3.

\section{Sentido del Tacto}

El tacto establece una forma de comunicación con el paciente además de aportar datos valiosos sobre el dolor, la forma, la consistencia, la presencia de neoformaciones, etc. El acto de colocar la mano sobre otro cuerpo es, en muchos sentidos, el sello distintivo del médico. También, no lo olvidemos, es un acto religioso (la conocida imposición de manos) por el que se infunde confianza, serenidad y resignación. Esto no debe extrañar dado que Asclepio ("El curador"), el padre de la medicina, hijo de Apolo y de Corónide fue instruido en las artes médicas por el centauro Quirón. Llegó a adquirir tal habilidad en la curación que llegó a resucitar a los muertos, razón por la que Zeus lo redujo a cenizas. En los templos de Asclepio, los enfermos se sometían a ayunos y abluciones, se vestían de blanco, ofrecían un sacrificio propiciatorio y se entregaban a un sueño profético. Por la noche aparecía el sacerdote-médico disfrazado de Asclepio y realizaba el acto médico imponiendo las manos, administrando fármacos e incluso practicando operaciones quirúrgicas ${ }^{28}$. De esta imposición de manos deriva "El poder sanador del contacto (que) forma parte de la cultura occidental desde hace mucho tiempo. Se

Tabla 3. Lo que el médico debe cuidar en su comunicación con el paciente porque los enfermos y sus familiares lo oirán ${ }^{39}$.

El médico no debe hablar demasiado, solo lo justo pero con claridad, de manera pausada. Tan malo es el médico que no habla y permanece en incómodos silencios como aquel que no para de hablar, como si fuera un charlatán de feria.

La voz no debe ser histriónica, sino dulce y sonora, y ha de llenar el espacio con un tono melódico y vibrante.

Debemos explicar al enfermo lo que va a hacer, lo que busca y todos los contenidos del acto médico. El enfermo necesita que le expliquen pormenorizadamente lo que le acontece por su derecho a tomar decisiones de manera activa y autónoma.

Nunca debe ser paternalista; el enfermo debe ser autosuficiente y maduro para tomar sus propias decisiones, y el médico debe informarles, explicarles las opciones, las expectativas, las evoluciones.

El médico debe huir de los términos técnicos para hacerse entender por el enfermo. 
dice que el profeta Elisha era capaz de devolver la vida a los muertos. Jesús colocaba sus manos sobre un leproso y este sanaba. Después de su resurrección, a sus discípulos les era concedido el poder de la sanación. Muchos santos obraban curaciones milagrosas con el contacto de sus manos"4, y aún hoy se continúa invocando la intercesión de algunos santos para alejar o cambiar la evolución de la enfermedad ${ }^{29}$.

Tocar al enfermo forma parte de una larga tradición humanitaria de la medicina a través de la cual se establece una profunda conexión entre médico y paciente. No obstante, no faltan médicos que consideran que la exploración no es más que una reliquia del pasado que puede ser sustituida por tecnologías que aportan información más eficaz y precisa. Sin embargo, es, probablemente, el sentido que más parece cohibir a los médicos, para los que parece preferible no exponerse a pasar un mal rato durante, por ejemplo, una exploración mamaria y a la "dificultad de interpretar las imágenes borrosas generadas por el tacto cuando una técnica puede mostrar las estructuras internas del cuerpo con mayor precisión y exactitud"4.

El tacto aporta mucha información, y en algunas patologías la información puede ocurrir de forma muy precoz, como es el caso de la exploración mamaria. Por tanto, deben hacerse esfuerzos complementarios en la formación de la ciudadanía y en la implementación de la adquisición de competencias por los estudiantes de medicina. Lisa Sanders describe la experiencia de aprendizaje en la palpación formativa de los pechos de una mujer instruida por una enferma tutora en los siguientes términos: Siga la línea de la clavícula hasta el punto donde se encuentra con el esternón-me instruyó-. Lo dijo con un tono de voz paciente, agradable, completamente relajado. Moví los dedos tímidamente, describiendo torpemente un círculo sobre la piel, el hueso y el cartílago. Cerca del esternón, una fina capa de grasa recubre el músculo mullido y robusto y las costillas. Un poco más abajo, la capa de grasa se hace más gruesa, en la región exterior de la prominencia que denominamos seno. No fue hasta que empecé a recorrer la segunda línea imaginaria que me topé con las densidades irregulares, similares a un dedo, de las glándulas mamarias, que apuntaban hacia el pezón como los radios de una rueda..."4. Lamentablemente, esta experiencia que en algunas universidades americanas se lleva a cabo mediante pacientes tutores está alejada de las prácticas curriculares de nuestros estudiantes.

En todo caso, la palpación puede realizar aportaciones precoces y diagnósticos rápidos que pueden ayudar a la toma de decisiones: "Mientras intentaba tranquilizar al asustado paciente McGee colocó la mano con suavidad en el cuadrante superior izquierdo de su abdomen. Palpó una inesperada resistencia en la zona normalmente mullida del vientre y unas pulsaciones tenues y regulares. Colocó la otra mano en el ombligo del paciente. Una masa depresible latía bajo sus dedos, empujándoselos hacia la derecha. Y aquello le dijo todo cuanto necesitaba saber. Llama a los cirujanos-dijo el residente-. Este hombre tiene que ingresar en quirófano inmediatamente. Tiene rotura de aneurisma aórtico abdominal"4.

Por último, nos recuerda el profesor Laín Entralgo ${ }^{16}$ que la experiencia táctil del enfermo tiene varios componentes: a) una vivencia de autoafirmación ("Me acarician, luego existo"), b) una vivencia de relajación que hace perder el tono muscular y facilita la exploración, y c) una vivencia de alivio y compasión que otorga comprensión. Además, no debemos olvidar que la forma médica de tocar se produce en un contexto de intimidad caracterizada por la distancia intelectual y emocional, y podemos entender que el paciente permite que el médico lo observe y lo palpe a cambio de que aplique sus conocimientos en beneficio del enfermo.

\section{¿QUÉ SABEMOS DE?

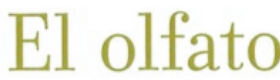

Laura López-Mascaraque y José Ramón Alonso

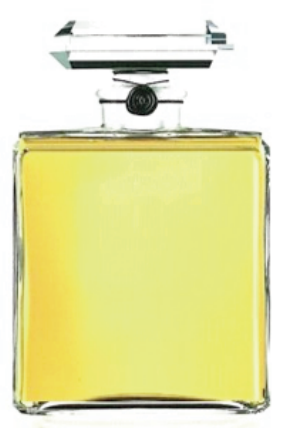




\section{Sentidos del Gusto y del Olfato}

Los sentidos de la vista, el oído y el tacto son sentidos físicos; en cambio, el del gusto y el del olfato son sentidos químicos que generalmente actúan en colaboración e incluso alcanzan su máxima expresión con la contribución del sentido de la vista. El sentido del gusto es muy plástico y tiene una gran capacidad de regeneración de sus elementos detectores, las papilas gustativas, que se recambian cada 10-14 días aproximadamente. El sentido del gusto reconoce cuatro sabores básicos (dulce, amargo, agrio y salado) a través de zonas más o menos especializadas en la percepción de cada uno de ellos.

El papel del sentido del gusto en medicina es, posiblemente, el menor de los cinco sentidos toda vez que queda lejos su papel relevante en el diagnóstico de la enfermedad dulce (diabetes sacarina) mediante la constatación del sabor dulce del dedo previamente sumergido en la orina del enfermo. No obstante, no son infrecuentes las consultas por alteraciones del gusto, entre las que se reconocen la ageusia (desaparición total del sentido del gusto o incapacidad para percibir sabores), la hipogeusia (cuando la percepción de los sabores está atenuada) y la disgeusia o parageusia (cuando la percepción de los sabores se ve alterada cualitativamente; es decir, se perciben sabores distorsionados en vez del sabor normal. En la mayoría de los casos puede identificarse un factor causal de la alteración del sabor. Entre ellos, son frecuentes las infecciones, las enfermedades subyacentes, la exposición a tóxicos o los tratamientos con medicamentos, sobre todo con aquellos que contienen grupos sulfidrilos que pueden comportarse como quelantes de zinc. En este caso, se asocian a disgeusias en las que predominan el sabor metálico 21,30 . Gracia Armendáriz nos ha dejado algún recuerdo gustativo de sus horas de hospital: "Olvidaré por unas horas (...) el sabor del suero en la bóveda del paladar"

Si bien el olfato es un sentido poco considerado en la medicina práctica, no es menos cierto que tiene un importante papel en la vida de relación y un inmenso poder evocador: "el olfato es el camino más corto a las emociones pues evoca recuerdos y tiempos pasados"31. También el sentido más emocional ya que los recuerdos de aromas y olores son mucho más intensos y duraderos que las imágenes o los sonidos. El olor, como otros aspectos biológicos, reconoce influencias relacionadas con la edad, el sexo, la condición social, el aseo, etc. Tal vez un ejemplo adecuado es el debatido "olor a viejo". Este olor, también denominado "olor de la gente mayor" existe y es reconocido en todas las culturas, si bien puede tener distintas interpretaciones y distintas génesis ${ }^{32}$. Digamos que

\section{Piel roja

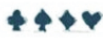

\author{
Juan Gracia Armendáriz
}
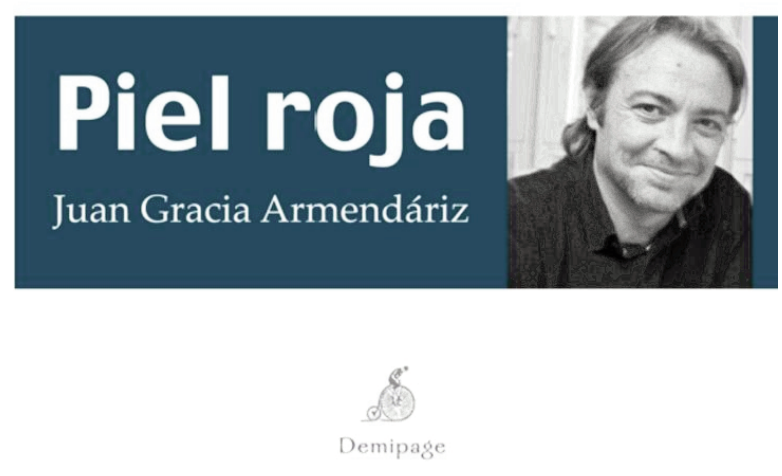

en los humanos el olor se produce por la interacción entre varias secreciones glandulares, entre ellas las sebáceas, que secretan sustancias que contribuyen al olor. Estas secreciones, al ser degradadas por los microbios de la piel, desprenden los componentes volátiles (alcoholes, cetonas y aldehídos), que otorgan la fragancia a cada uno de nosotros, olor que cambia a lo largo de la vida. "Se cree que los compuestos aldehídicos son los que atribuyen ese peculiar olor, en especial a los mayores de 60 años"3. También es conocido que, dado que cada persona tiene su personal perfil de bacterias dermatológicas, el olor de cada una es personal y sirve para identificarla. Sin embargo, a diferencia de otros mamíferos, los humanos consideramos el olor corporal algo inútil, prescindible e incluso molesto y hacemos considerables esfuerzos por librarnos de él mediante el uso de perfumes para eliminarlo o enmascararlo.

A pesar de que el olfato es uno de los sentidos menos valorados, en una Encuesta sobre los sentidos "el $36 \%$ de los encuestados rechazaría a una persona por su olor, frente al 12\% que lo haría por su físico"3. Y es que el olor no sólo está presente en todas nuestras actividades cotidianas sino que condiciona algunas de ellas. El autor 
francés Philippe Claudel 33 ha recogido, a lo largo de 63 capítulos, en una historia personal de los olores una panoplia de aromas que marcan toda su vida, incluida una alusión a la muerte que "huele a éter" o al robo del olor del padre durante el proceso de acondicionamiento post-morten: "cuando lo beso, no huele a él. Apesta a mujer y a medicamento. Una original mezcla de formol y polvos de arroz, de base de maquillaje y producto alcanforado". A esta percepción del olor de la muerte se refiere también Samuel Shem ${ }^{34}$ en La Casa de Dios: "El olor era el que la muerte deja: un olor mórbidamente agrio, un olor febril, un olor que se iba perdiendo en dirección a un lejano horizonte que yo apenas podía vislumbrar." Y es que los aromas son una poderosa herramienta literaria como demuestra la obra El Perfume, de Patrick Süskind. La propia literatura nos indica que parece posible que hombres y mujeres tengamos una diferente sensibilidad a los olores. En su último libro, Coetzee ${ }^{35}$ incluye el relato La anciana y los gatos en el que una mujer ha decidido pasar los últimos años de su vida en un pueblo casi deshabitado. Cuando el hijo la visita para intentar convencerla de que lo acompañe, encuentra que en la casa vive también un hombre mayor y desaliñado, al que la madre ha acogido, y que le hace ponerse en guardia.

- ¿Se lava? -le pregunta a la madre-. Veo que no se lava los dientes. No entiendo cómo puedes soportarlo cerca.

- La madre se ríe divertida: Imagínate lo que sería tener relaciones sexuales con él. Lo cierto es que a los hombres en general no les importa el olor que tienen. Las mujeres somos distintas"35.

Desde el punto de vista médico, el olfato aporta información sobre el estado funcional de glándulas exocrinas, de la respiración, etc. Hasta el punto de que hay olores característicos de algunas afecciones: el olor a acetona, el olor a almendras amargas, el olor característico de algunos medicamentos y sustancias que se eliminan por vía respiratoria,..., que pueden informar sobre la exposición de ciudadanos o enfermos a determinadas sustancias, pueden ser útiles desde el punto de vista diagnóstico o para el seguimiento de determinados tratamientos.

Pero también son importantes las alteraciones, transitorias o permanentes, del sentido del olfato que implican la pérdida de la habilidad de oler o la percepción distorsionada de los olores. Las alteraciones cuantitativas incluyen anosmia (pérdida completa de la capacidad para detectar o reconocer los olores), hiposmia (pérdida parcial del olfato), e hiperosmia (aumento exagerado de la sensibilidad olfativa); las alteraciones cualitativas incluyen la

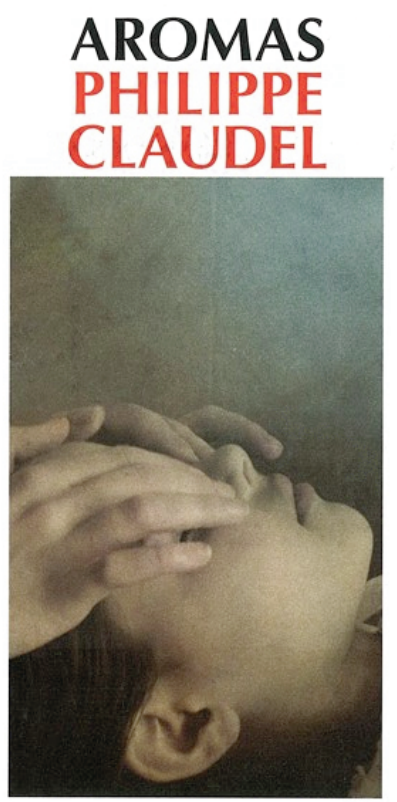

$$
\text { Halamandra }
$$

disosmia (distorsión de la sensación olfativa), la parosmia (los odorantes específicos se perciben de manera diferente, bien como placenteros (euosmia) o desagradables (cacosmia), y fantosmia (distorsión que consiste en percibir olores cuando no hay estímulo olfativo presente). Estas alteraciones pueden ser congénitas (ej. anosmia congénita) o consecutivas a alteraciones de las vías respiratorias altas, inflamaciones nasosinusales, traumatismos craneales, tumores nasales o cerebrales y alteraciones hormonales 31 .

Por otra parte, el mundo de la actividad sanitaria está circundada de olores, incluyendo el característico olor a antiséptico de los hospitales, percibido como nauseabundo por algunos enfermos ("temo el olor nauseabundo de la asepsia"20, pero también el olor del material de curas ("olía a vendas y a yodo"; "El penetrante olor de la pomada antiinflamatoria" 36 , o el olor de la habitación del enfermo ("De nuevo, el olor estadizo de la habitación: el hervor de la comida que asciende bajo los cuencos de aluminio, la lejía extendida en el baño, el de mi propio cuerpo, que ha impregnado las sábanas revueltas. Los olores agrios y pesarosos de una habitación de hospital"21. 
Tabla 4. Algunos ejemplos de olores que pueden ser percibidos por el médico (A) y de olores emanados por el médico que el enfermo puede percibir (B) tomados de diferentes obras literarias.

\begin{tabular}{|c|c|}
\hline Autor & Expresión \\
\hline \multicolumn{2}{|l|}{ A. Percibidos por el médico } \\
\hline Sanders, $2010^{4}$ & $\begin{array}{l}\text { "Su piel estaba caliente y olí la fragancia del jabón o el desodorante que se } \\
\text { había puesto aquella mañana". }\end{array}$ \\
\hline Puleo, $2013^{40}$ & $\begin{array}{l}\text { "El olor punzante de la sangre impregnaba el aire" "El olor punzante a alcohol y } \\
\text { a medicamentos, pero también a muerte, a miedo, a sufrimiento y a lágrimas" }\end{array}$ \\
\hline Prieto, $2014^{41}$ & $\begin{array}{l}\text { "El cadáver era un mulato fondón en la cincuentena, nariz chata y pelo ensor- } \\
\text { tijado. Olía a colonia cara." }\end{array}$ \\
\hline Arís, $2007^{42}$ & $\begin{array}{l}\text { "Nada más entrar en el que iba a ser su destino en los próximos meses, el sen- } \\
\text { sible olfato de Ken percibió el olor característico de aquel lugar, en el que se } \\
\text { entremezclaban el limpio aroma del desinfectante con la fetidez de una huma- } \\
\text { nidad desaseada, hacinada y, en ocasiones, supurosa" }\end{array}$ \\
\hline Bono, $2017^{43}$ & $\begin{array}{l}\text { "Nadie debería morir así, entre gritos y carreras, entre desconocidos que huelen } \\
\text { a nada" }\end{array}$ \\
\hline Cline, $2016^{44}$ & "La ropa interior saturada del olor amargo de la orina" \\
\hline Díaz-Mas, $2016^{45}$ & "Huele a jabón y a colonia infantil: se conoce que la acaban de bañar" \\
\hline \multicolumn{2}{|l|}{ B. Percibidos por el enfermo } \\
\hline Schweblin, $2015^{46}$ & $\begin{array}{l}\text { "¿Cómo se siente hoy la señora? Eso preguntó el médico del hospital las tres o } \\
\text { cuatro veces que fue a verla a la casa. Siempre estaba acalorado, Lola podía } \\
\text { oler su traspiración, algo que ella no consideraba higiénico tratándose de un } \\
\text { médico." }\end{array}$ \\
\hline Sergio del Molino, $2013^{18}$ & $\begin{array}{l}\text { "Exuda un aroma refinado que yo identifico con la decencia" (sobre una de las } \\
\text { médicas que atendió a su hijo Pablo). }\end{array}$ \\
\hline Gracia Armendáriz, $2008^{36}$ & $\begin{array}{l}\text { "Una vez que el director del departamento de nefrología ha apretado, uno a } \\
\text { uno, los pies de todos los pacientes se alejan por el pasillo formando un grupo } \\
\text { hermético de hombres saludables y recién duchados que dejan a su paso un } \\
\text { agradable olor a agua de colonia" }\end{array}$ \\
\hline Gracia Armendáriz, $2012^{21}$ & $\begin{array}{l}\text { "El joven urólogo viene a comprobar la evolución de la cicatriz. Desprendo el } \\
\text { velcro de la faja abdominal. Respiro, aliviado. Cuando se inclina sobre la cicatriz } \\
\text { huelo el perfume que emana de su cuello. Huele a señora rica" }\end{array}$ \\
\hline Shriver, $2012^{47}$ & $\begin{array}{l}\text { "El doctor Edward Knox le tendió la mano a Shep, un apretón firme y generoso. } \\
\text { El oncólogo emitía el olor astringente y penetrante del antiséptico, como si } \\
\text { fuese uno de los raros médicos que de veras se lavaban las manos. Era un olor } \\
\text { que Shep asociaba con la angustia" }\end{array}$ \\
\hline Meruane, $2012^{48}$ & $\begin{array}{l}\text { "Sé que usted fuma a escondidas, a escondidas de su mujer, de sus pacientes y } \\
\text { de Doris sobre todo, a escondidas de usted mismo. Puedo oler los residuos del } \\
\text { tabaco en su aliento". }\end{array}$ \\
\hline Taranilla, $2015^{49}$ & $\begin{array}{l}\text { "Como de la nada apareció una doctora. (...) Era la primera vez que la veía. He } \\
\text { olvidado su cara, pero recuerdo que era una mujer madura y sonriente. (...) Olía } \\
\text { bien. Estoy segura de ello porque la tuve unos minutos muy cerca de mi". }\end{array}$ \\
\hline
\end{tabular}

$\mathrm{Y}$, sin lugar a dudas, todos recordamos el olor a medicamentos que inunda cualquier estancia donde se acumulan: "El olor a medicina del cuarto donde nos pasábamos los días y las noches, separadas del resto de los habitantes de la casa, mi madre y yo", escribe Soledad Puértolas a propósito del tifus que contrajeron su madre y ella y por el que pasaron un mes recluidas en un cuarto de la casa $^{37}$. 


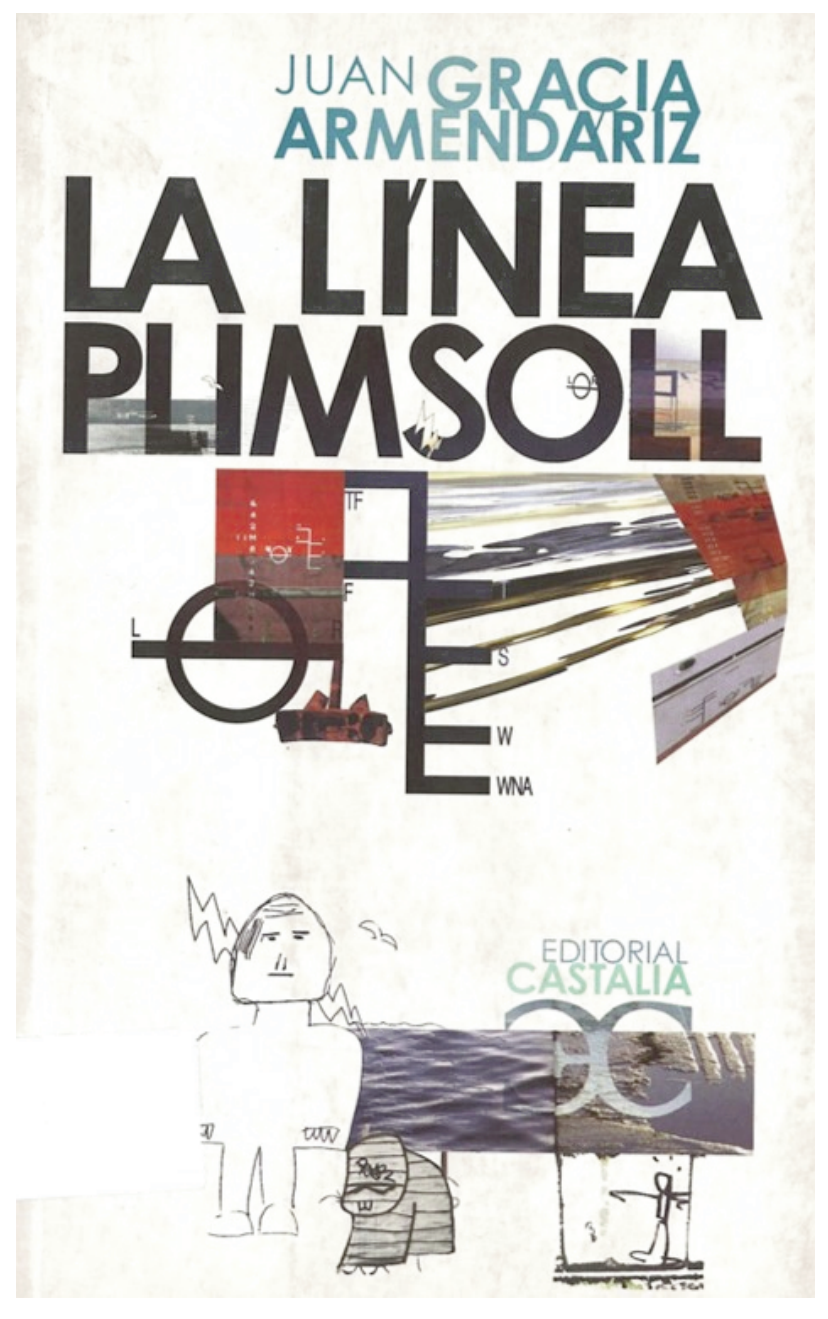

También fuentes literarias informan del potencial efecto terapéutico de los olores, de que hay olores que curan. Matt Haig en su libro Razones para seguir viviendo 38 incluye, dentro del capítulo "cosas que me ponen mejor" en el proceso de recuperación / reversión o salida de la depresión, "el olor del pan". No indica a qué atribuye el efecto benéfico, aunque tal vez se trate de la evocación de la infancia, de un hogar acogedor, de los trabajos artesanales, o de cualquier otra cosa, que genera el olor.

El médico puede percibir en el enfermo y en el entorno toda una panoplia de olores, algunos de los cuales se muestran en la Tabla 4A. Pero También el olor del médico es importante, es percibido por el enfermo y utilizado para elaborar un perfil particular de los profesionales sanitarios. La Tabla 4B muestra algunos fragmentos extraídos de libros de diferente origen que inciden en el olor de los médicos.

\section{Referencias}

1. Hipócrates. Sobre la ciencia médica. En Tratados Hipocráticos. Madrid: Gredos; 2000. p 11-24.

2. Criado MA. La jerarquía casi universal de los cinco sentidos. El País, 25 de enero de 2015.

3. Redacción. El Médico Interactivo. El valor de los cinco sentidos. 19 de Agosto de 2011.

4. Sanders L. Diagnóstico. Barcelona: Random House Mondadori; 2010.

5. Vilardell M. Ser médico. El arte y el oficio de curar. Barcelona: Plataforma Editorial; 2009.

6. Sacks O. En movimiento. Una vida. Barcelona: Anagrama; 2015

7. Ibarias JJ. Decálogo del buen médico. Cáceres, SEMFYCEX [Internet] [consultado 20 de marzo de 2019].

8. Cantabrana B, Hidalgo A. Una experiencia de aproximación a la clínica en el primer curso del Grado en Medicina de la Universidad de Oviedo. FEM 2018; 21(1): 31-9.

9. Hidalgo A, Bordallo J, Cantabrana B. Utilidad potencial de las artes visuales en la enseñanza de la medicina. Educ Med 2018a; 19 (S3): 284-93.

10. Hidalgo A, Hidalgo C, Cantabrana B. Observación y descripción de obras de arte en la enseñanza de la medicina. Una experiencia en la Universidad de Oviedo. Rev Med Cine 2018; 14(2):115-22.

11. Elder AT, McManus IC, Patrick A, Nair K, Vaughan L, Dacre J. The value of the physical examination in clinical practice: an international survey. Clin Med (Lond). 2017;17(6):490-8.

12. Millán J. Semiología clínica: ¿Quo vadis?. Educ Med. 2018; 19(6): 319.

13. Pera C. Pensar desde el cuerpo. Ensayo sobre la corporeidad humana. Madrid: Triacastela; 2006.

14. Roueché B. El hombre naranja. En El Médico detective. Barcelona: Alba; 2011. 15. Martínez, P. Carlos Jiménez Escolano: Desde que tienen ordenador, los médicos no miran a los pacientes a la cara. La Nueva España, 5 de septiembre de 2015. 16. Laín Entralgo P. El médico y el enfermo. Madrid: Ediciones Guadarrama; 1969. 17. Pera C. El cuerpo silencioso. Ensayos mínimos sobre la salud. Madrid: Triacastela; 2009.

18. Molino S del. La hora violeta. Barcelona: Mondadori; 2013.

19. Larraquy R. La comemadre. Turner: Madrid; 2014.

20. Gracia Armendáriz J. Diario del hombre pálido. Madrid: Demipage; 2010.

21. Gracia Armendáriz J. Piel Roja. Madrid: Demipage; 2012.

22. Ortega Pérez CA. El lado humano de la medicina. Jaén: Formación Alcalá; 2012.

23. Bayés, R. Aprender a investigar, aprender a cuidar. Barcelona: Plataforma Actual; 2012.

24. Riera J. Historia, Medicina y sociedad. Madrid: Pirámide; 1985.

25. Laennec RTJ. Tratado de la auscultación mediata. Madrid: Instituto Arnaldo de Vilanova. CSIC; 1954.

26. Foucault M. El nacimiento de la clínica. Una arqueología de la mirada médica. Madrid: Siglo XXI; 2006.

27. Sontag S. El SIDA y sus metáforas. En La enfermedad y sus metáforas. El sida y sus metáforas. Barcelona: De Bolsillo, 2011.

28. Szczeklik A. Catarsis. Sobre el poder curativo de la naturaleza y del arte. Barcelona: Acantilado; 2010.

29. Vilanova JM. Santas y santos sanadores: historia, leyendas, gozos. Barcelona: Editorial Mediterrànea; 2007.

30. Bateman N, Kerr S. Trastornos gastrointestinales. En Lee A, director. Reacciones adversas a los medicamentos. Barcelona: Pharma Editores; 2007. p. 155-187.

31. López-Mascaraque L, Alonso JR. El olfato. Madrid: Catarata-CSIC; 2017

32. ABC.es. El mito del "olor a Viejo". ABC, 30 de mayo de 2012.

33. Claudel P. Aromas. Barcelona: Salamandra; 2013.

34. Shem S. La casa de Dios. Barcelona: Anagrama, 6a ed.; 2009.

35. Coetzee JM. La anciana y los gatos. En Siete cuentos morales. Madrid: El hilo de Ariadma, 2018.

36. Gracia Armendáriz J. La línea Plimsoll. Madrid: Editorial Castalia; 2008. 
37. Puértolas S. Con mi madre. Barcelona: Anagrama; 2001.

38. Haig M. Razones para seguir viviendo. Barcelona: Seix Barral; 2016.

39. Zarco J. El arte de ser médico. Sanar, cuidar, acompañar. Barcelona: Península; 2013.

40. Puleo A. Escucharás mi corazón. Barcelona: Penguin Random House 5ạ ed; 2013.

41. Prieto S. Palabras de muerte. En Cuentos del Fonendoscopio. Madrid: Editorial Tébar Flores; 2014.

42. Arís, A. Los cuadros del anatomista. Madrid: Suma de las letras; 2007.

43. Bono I. Una casa en Bleturge. Madrid: Siruela; 2017

44. Cline E. Las chicas. Barcelona: Anagrama; 2016.

45. Díaz-Mas P. Lo que olvidamos. Barcelona: Anagrama; 2016.

46. Schweblin S.- La respiración cavernaria. En Siete casas vacías. Madrid: Páginas de Espuma, 2015

47. Shriver L. Todo esto para qué. Barcelona: Anagrama; 2012.

48. Meruane, L. Sangre en el ojo. Madrid: Caballo de Troya; 2012.

49. Taranilla R. Mi cuerpo también. Barcelona: Los libros del lince; 2015.
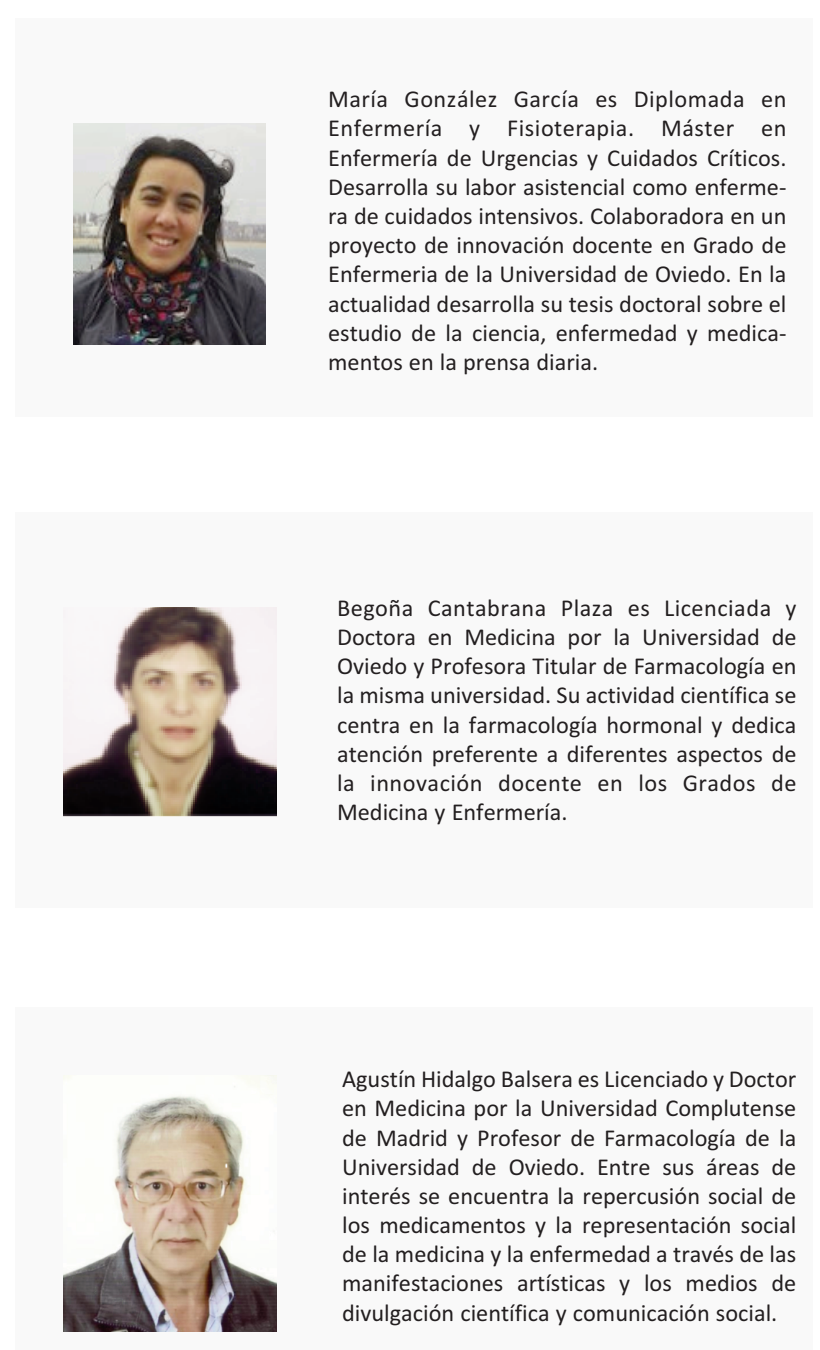